\title{
EDITOR'S REPORT, 1946
}

During 1946 Volume XXII of the "Forestry Chronicle" was published in four issues in March, June, September and December. The first three of these issues were distributed on time, that is to say, at the end of March, June and September respectively. The December issue, however, was not distributed until January 5, 1947. This delay was caused, firstly, by the extension of the dead-line so as to permit the inclusion of copy descriptive of the 1947 annual meeting; and, secondly, by slow Christmas mails which lengthened the usual mailing time between Montreal and Oshawa from one day to one week.

As in the past the printing and distribution were handled by Messrs. Mundy, Goodfellow Printing Co. Ltd., Oshawa, Ontario. With the exception of the December delay which was unavoidable there was no other undue delays between the date of receipt of the original copy by the printers and the final distribution. This represented considerable improvement over 1945 when there had been serious delays on account of labour shortages and machine breakdowns. Another very decided improvement effected by the printer was in the scoring of the covers. Late in 1945 there had been a changeover from glossy green to rough caste green for cover stock, but whereas the scoring had been quite satisfactory on the glossy stock it was so indaequate on the rough caste stock that covers frequently separated from the white pages at first opening of the issue. The scoring has now been adjusted to meet the needs of the rough caste cover stock, and troubles in this connection have been largely eliminated though there is still room for improvement.

The March issue featuring news of the annual meeting of the Society at Regina and including reports of standing committees was the largest. It had 108 pages, 3 half tone cuts, 2 zinc line cuts, and cost $\$ 403.43$.

The June issue had 88 pages, 3 half tone cuts, one zinc line cut, and cost $\$ 360.60$.

The September issue had 80 pages, 6 half tone cuts, one zinc line cut, and cost $\$ 332.01$.

The December issue had 76 pages, 4 half tone cuts, and cost $\$ 328.84$

The total cost of Volume XXII was $\$ 1,419.88$ against a budget of $\$ 1,500.00$. There was therefore a surplus of $\$ 80.12$.

At the General Executive Committee meeting at Regina in January, 1945, it was decided on account of increased printing costs to raise the budget from $\$ 1,000$ to $\$ 1,500$. At that time it was not known exactly what these increased costs would be, and, in fact, the revised schedule of prices was not received from the printers until July. For this reason we had to plan each issue so as to eliminate all expenditures which were not absolutely necessary and to limit experimentation to a minimum. Thus, though directed by the General Executive to feature more photographs and though obtaining during the year about thirty photographs which were suitable for publication, we decided that in view of the additional printing costs it would be impossible to reproduce all of these without going into the red. However, we did manage to reproduce 16 half tones and 4 zinc line cuts as compared with 23 
half tones and 8 zinc line cuts in 1945. Moreover, these photographs were more uniformly distributed (approximately four to an issue) than in 1945 when one issue had 13 photographs and another issue had none.

The following table is indicative of more comparisons between this and preceding volumes:-

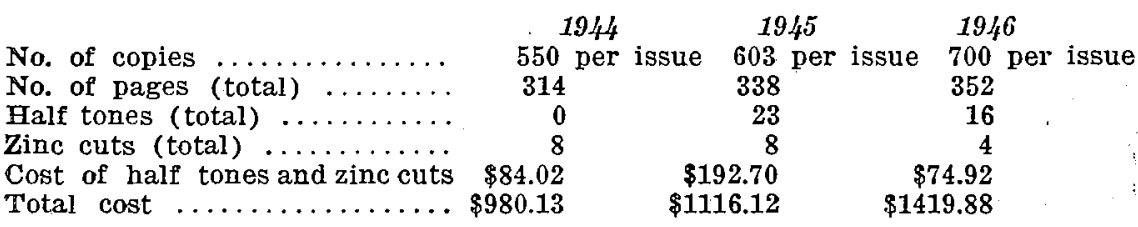

It is to be noted that the number of copies distributed has increased to 700. This is accounted for both by increased membership and by the fact that forestry and allied organizations all over the world have been asking for complimentary exchange copies in increasing numbers. A further record for Volume XXII which must be duly entered in the book is that it had more pages than any previous volume, also the greatest number of articles (namely 26) ever contributed in any one year.

Mention should be made of the December issue which was devoted almost entirely to a discussion of forest education. Articles descriptive of forest education at each of the four university forest schools across Canada were featured therein, and it is hoped that this focussing of attention on this basic forestry theme will develop interest in and understanding of the problems of forest education. It is suggested that other basic themes might be treated similarly in subsequent issues of the "Forestry Chronicle".

When the editorship was assumed by the present incumbent he resolved that-good, bad, or indifferent - there would always be an editorial in every issue. To date it can be reported that this resolution has been kept to the letter-there have been editorials, good, bad and indifferent, in every issue.

An index of Volume XXII was published as an integral part of the December issue.

The Canadian Pacific Airlines Ltd., Montreal, loaned two blocks for the March issue. The Department of Agriculture at Ottawa contributed the sum of $\$ 14.74$ towards the cost of half-tones in the September issue. We acknowledge and are grateful for both these contributions.

We appreciate the cooperation received from the secretary-treasurer, the General Executive, and members of the Editorial Board. Bouquets to the latter for their reporting of section activities, especially for their December showing when reports were received from every single section without ex. ception. We hope that this one hundred per cent coverage will be continued as standard practice in 1947.

Respectfully submitted,

K. G. Fensom,

Editor and Chairman of

the Editorial Board. 